Article

\title{
Carbon Efficient Building Solutions
}

\section{Miimu Airaksinen ${ }^{1, *}$ and Pellervo Matilainen ${ }^{2}$}

1 VTT Technical Research Centre of Finland, P.O. Box 1000, FI-02044 VTT, Finland

2 Skanska M\&E Finland Oy, P.O. Box 114, FI-00101 Helsinki, Finland;

E-Mail: pellervo.matilainen@skanska.fi

* Author to whom correspondence should be addressed; E-Mail: miimu.airaksinen@vtt.fi;

Tel.: +358-40-770-4832; Fax: +358-20-722-7009.

Received: 1 February 2010; in revised form: 24 February 2010 / Accepted: 1 March 2010 /

Published: 23 March 2010

\begin{abstract}
Traditionally, the Finnish legislation have focused on energy use and especially on energy used for heating space in buildings. However, in many cases this does not lead to the optimal concept in respect to minimizing green house gases. This paper studies how $\mathrm{CO}_{2}$ emission levels are affected by different measures to reduce energy use in buildings. This paper presents two real apartment buildings with different options of energy efficiency and power sources. The calculations clearly show that in the future electricity and domestic hot water use will have high importance in respect to energy efficiency, and therefore also $\mathrm{CO}_{2}$ equivalent (eq) emissions. The importance increases when the energy efficiency of the building increases. There are big differences between average Finnish production and individual power plants; $\mathrm{CO}_{2}$ eq emissions might nearly double depending on the energy source and the power plant type. Both a building with an efficient district heating as a power source, and a building with ground heat in addition to nuclear power electricity as a complimentary electricity source performed very similarly to each other in respect to $\mathrm{CO}_{2}$ eq emissions. However, it is dangerous to conclude that it is not important which energy source is chosen. If hypothetically, the use of district heating would dramatically drop, the primary energy factor and $\mathrm{CO}_{2}$ eq emissions from electricity would rise, which in turn would lead to the increase of the ground heat systems emissions. A problem in the yearly calculations is that the fact that it is very important, sometimes even crucial, when energy is needed, is always excluded.
\end{abstract}

Keywords: energy efficiency; primary energy; building concepts 


\section{Introduction}

Buildings account for circa 40\% of the total energy use in Europe [1] and for about 36\% of the EU's total $\mathrm{CO}_{2}$ emissions, including the existing energy conservation in buildings [2]. Even though energy saving measures at building level have been proposed, the net energy use at city/district level is still increasing. Buildings are important in achieving the EU's energy savings target and to combat climate change while contributing to energy security. As the European strategic energy technology plan (SET-PLAN2007 [3]) states, strategies to improve energy efficiency at each level (energy conversion, supply and end-use) should be better imposed. In addition to the natural environment, the built environment has a large impact on the economy, health and productivity. Globalization is one of the reasons for increasing energy use, since it has spread the lifestyle of the most developed Western countries to a worldwide level, changing the expectations about the quality of life in many societies to a point where sustainability is no longer possible on a large scale. The energy use of buildings is one lifestyle aspect that causes a high environmental pressure in developed countries. Building industry and the built environment are one of the largest contributors to energy and material use worldwide. In the northern part of the European Union, $41 \%$ of the total final energy use comes from buildings, with $30 \%$ being used in residential buildings [4]. According to the report of EuroACE [5], 57\% of the energy used in buildings is for space heating, $25 \%$ for hot water, $11 \%$ for lighting and electrical appliances, and 7\% for cooking. Currently, governments are making large efforts towards policies and regulations aimed at increasing the energy efficiency of buildings. An example of such initiatives is the EPBD, which from 2003 has asked all European member states to implement energy regulations aimed at decreasing energy use in buildings in relation to heating, cooling, ventilation, lighting and domestic hot water. In addition, efforts to construct low energy buildings can be observed in several projects and studies worldwide.

Buildings are an exceedingly complex industrial product with a lifetime of decades. Emerging health issues related to the environmental impacts of buildings, such as the so-called "sick building" syndrome, have intensified awareness of the role buildings play in our environmental wellbeing. While certain efforts have been on-going to control and manage individual aspects of the environmental qualities of buildings (i.e., energy codes, automation and control schemes, thermal comfort), comprehensive approaches have been lacking [6,7], particularly in the design stages of a building's life span. Unfortunately, it is in the design stage when the greatest opportunities are available to affect changes whose benefits can last for decades.

In Finland, residential and commercial buildings account for $40 \%$ of all energy use, in addition commercial and apartment buildings have a notable influence on the peak demand in some periods. Energy and electric intensity in commercial buildings has clearly increased, and residential energy use continues to increase (mainly due to electricity use). Yet, technologies and knowledge exist that could be used to create better, high-performance buildings. Combining such technologies with better system integration could cost-effectively achieve savings as high as $30 \%$ in new buildings, compared to the minimum requirements in building code. Existing retrofit technologies and retro-commissioning practices could provide economically efficient additional energy savings in existing buildings. 
Traditionally, the design, construction, and/or operation practices were, and in many cases still are, rather fragmented. That is, the major barrier to allow the timely and effective implementation and integration of energy efficiency methods and technologies on every new building and renovation project.

In the worst case, the main criterion for decision making about design alternatives are cost and aesthetics. Therefore, unfortunately in many cases decision making in early project phases, when the influence on the overall project performance is largest, is mostly based on what can be seen (aesthetics) and what can be quantified relatively easily (initial cost). This process minimizes cost at every step, but does not describe when and how to consider other criteria, such as energy concerns and end-user needs, thus limiting the incorporation of such lifecycle knowledge into the planning and design process in a consistent, predictable, and valuable way; the incorporation of methods and technologies for energy efficiency comes often as an afterthought. The lack of a more integrated design, construction, and operation process leads to the following three main problems:

1. Ineffective Design: The best or most effective building is rarely designed and built. For example, the "wrong" square footage is often built, which has little functional value and uses energy to heat and cool.

2. Ineffective Operation: End users often do not know how to operate the building to minimize energy use, which, in some cases, has led to buildings using twice the amount of energy originally calculated by the design team.

3. Lack of Feedback Learning: Feedback loops from the use phase to the design phase are rare, making learning about effective methods and technologies slow and haphazard.

Currently, lifecycle energy efficiency, the resulting value and corresponding cost savings are not key criteria in the building development process, which makes it unlikely that every building is designed to maximize the use of energy efficient building design and technology options for a particular site, building, and use. A major challenge to professionals will be how to integrate the growing list of requirements and models into multidisciplinary design and analysis processes that produce effective buildings.

Due to reasons mentioned earlier, it is evidently very important not only to minimize energy use, but in addition to choose less polluting energy sources. This decision is complicated, since not only greenhouse gases are harmful, but also toxic to water systems or ground soil. This can occur from the product manufacturing process and during the construction process. In addition, how long we should follow the path from energy use to energy source can be hard to decide. Due to the very complex nature of this question, here we limit our calculations only to building energy use $\mathrm{CO}_{2}$ equivalent (eq) emissions. In addition, this study does not take into account the quality of energy, but only the used energy and the primary energy. The disadvantage of this kind of approach is that it does not see the benefits if a waste energy from other systems is used, e.g., low temperature heating system using waste heat from another system. However, the approach here represents the conventional way to connect buildings in an energy network, and this approach was chosen in this study because the case studies here are actual buildings and due to the building site and construction process there was no other alternatives than the conventional way. In the future, the importance of the quality of energy will be highlighted, especially when renewable energy sources or waste energy sources are used. 


\section{Methods}

The buildings studied were two Skanska's apartment buildings (Gardenia and Satamawouti) in design phase, Figure 1. In order to compare the buildings easily, the buildings in this study were assumed to be located in the Helsinki capital area, even though Satamawuoti is actually being constructed $200 \mathrm{~km}$ north of Helsinki. Both buildings were in design phase and the aim was to study the best alternatives to reduce greenhouse gas emissions.

Figure 1. Studied buildings (a) Gardenia (b) Satamawouti.

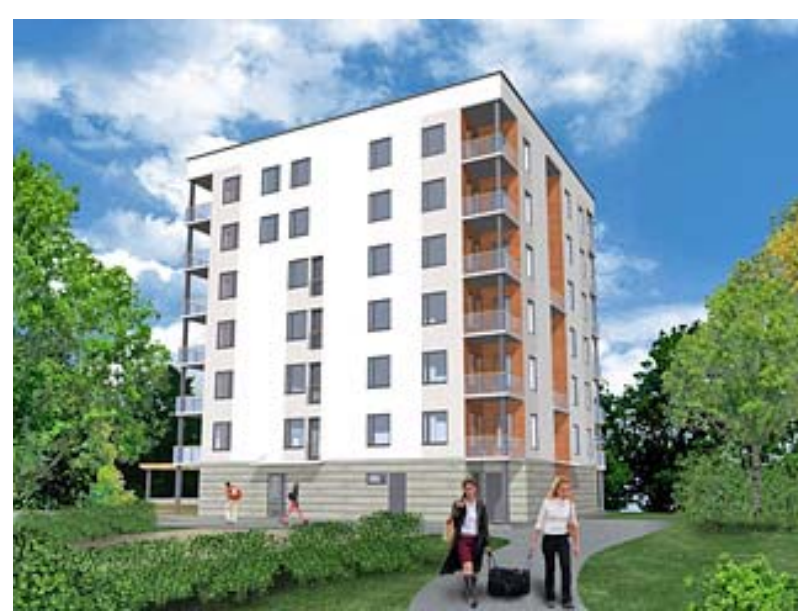

(a)

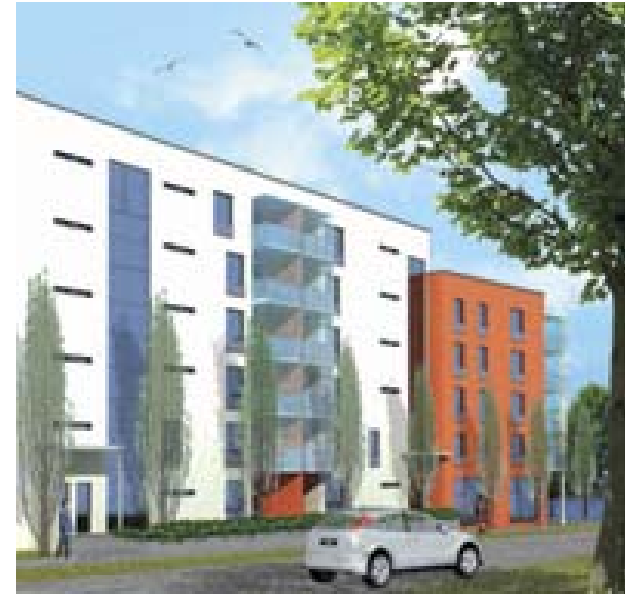

(b)

The buildings were modeled in a dynamic IDA simulation environment [8], where a RC-network (resistance-capacitance network) model of a building was used. The buildings were simplified to one zone models, and for users a typical profile according to Finnish energy calculation standards was used.

IDA is a modular simulation environment, which consists of a translator, solver, and modeler. The solver and physical models are separated, which makes it possible to change the mathematical formula of any component without changing the model description file. The modules are written in Neural Model Format (NMF), which serves at the same time as a readable document and a computer code. Via the translator, the modules can be used in several modular simulation environments [9-11].

Three levels of energy use in both buildings were calculated. The basic level used today's building code (BC 2008). Two other levels were the Finnish building code level 2010 (BC 2010) and the assumed building code level 2012 (BC 2012). The properties used in the calculations are shown in Table 1.

The used COP (coefficient of performance) for ground heat pump energy is 3.5 for space heating and 2.7 for domestic hot water. Due to the cold Finnish climate, it was assumed that $15 \%$ of the time heat pumps could not supply all heat needed, and therefore extra power was needed. That power was either assumed to be from nuclear power plants or coal plants. $\mathrm{CO}_{2}$ eq emissions from electricity and district heating were calculated from the average emissions in Finnish power plants. However, for example, the Helsinki city energy production company, Helen, gives lower values; $120 \mathrm{gCO}_{2} / \mathrm{kWh}$ for district heating and $260 \mathrm{gCO}_{2} / \mathrm{kWh}$ for electricity in combined production. This was also used in the 
calculations as a one case example for showing how different the combined district heating and electricity power plants can be in the sense of $\mathrm{CO}_{2}$ eq emissions and primary energy. The used primary energy factors and $\mathrm{CO}_{2}$ equivalent emissions are shown in Table 2.

Table 1. The properties of the studied buildings used in the calculations.

\begin{tabular}{|c|c|c|c|c|c|c|}
\hline & \multicolumn{2}{|c|}{ BC 2008} & \multicolumn{2}{|c|}{ BC 2010} & \multicolumn{2}{|c|}{ BC 2012} \\
\hline & Gardenia & Satamawouti & Gardenia & Satamawouti & Gardenia & Satamawouti \\
\hline Envelope air tightness $n_{50}(\%)$ & 4 & 4 & 2 & 2 & 1 & 1 \\
\hline Ventilation heat recovery (\%) & 30 & 30 & 50 & 50 & 70 & 70 \\
\hline Air change rate $(1 / \mathrm{h})$ & 0.7 & 0.5 & 0.7 & 0.5 & 0.7 & 0.5 \\
\hline $\operatorname{Roof}\left(\mathbf{W} / \mathbf{m}^{2} \mathbf{K}\right)$ & 0.16 & 0.16 & 0.09 & 0.09 & 0.09 & 0.09 \\
\hline Exterior wall (W/m²K) & 0.24 & 0.24 & 0.14 & 0.14 & 0.14 & 0.14 \\
\hline Base floor $\left(\mathbf{W} / \mathbf{m}^{2} \mathbf{K}\right)$ & 0.2 & 0.2 & 0.14 & 0.14 & 0.14 & 0.14 \\
\hline Window $\left(\mathbf{W} / \mathbf{m}^{2} \mathbf{K}\right)$ & 1.3 & 1.4 & 1 & 1 & 1 & 1 \\
\hline Balcony door (W/m² $\mathbf{2})$ & 1.4 & 1.4 & 0.07 & 0.07 & 0.07 & 0.07 \\
\hline $\operatorname{Door}\left(\mathbf{W} / \mathbf{m}^{2} \mathbf{K}\right)$ & 1.8 & 1.4 & 0.07 & 0.07 & 0.07 & 0.07 \\
\hline
\end{tabular}

Table 2. The used primary energy factors and $\mathrm{CO}_{2}$ equivalent emissions.

\begin{tabular}{|l|c|c|}
\hline & $\begin{array}{c}\text { Primary } \\
\text { energy factor }\end{array}$ & $\begin{array}{c}\mathbf{C O}_{2} \mathbf{~ e q} \\
\mathbf{k g ~ C O} \mathbf{~ C} / \mathbf{k h}\end{array}$ \\
\hline District heating average & 1.87 & 220 \\
District heating Helsinki & 0.4 & 120 \\
Electricity average & 1.87 & 380 \\
Electiricity from district heating average & 1.87 & 380 \\
Electiricity from district heating Helsinki & 2.5 & 260 \\
Peak electricity from nuclear power & 2.8 & 0 \\
Peak electricity from coal & 2.0 & 928 \\
\hline
\end{tabular}

\section{Results}

\subsection{Heat Losses}

The heat losses were dominated by ventilation and windows, which accounted for $65-75 \%$ of the losses, depending of the case, Figure 2. Even though the buildings differed in shape and occupied roughly the same amount of window area per floor area, there was not a clear sign that the combined form and shape would give much benefit. However, both buildings were compact in shape and efficient in the sense of heat losses. 
Figure 2. Heat losses in studied building cases. The BC values are estimated since they are not published yet.

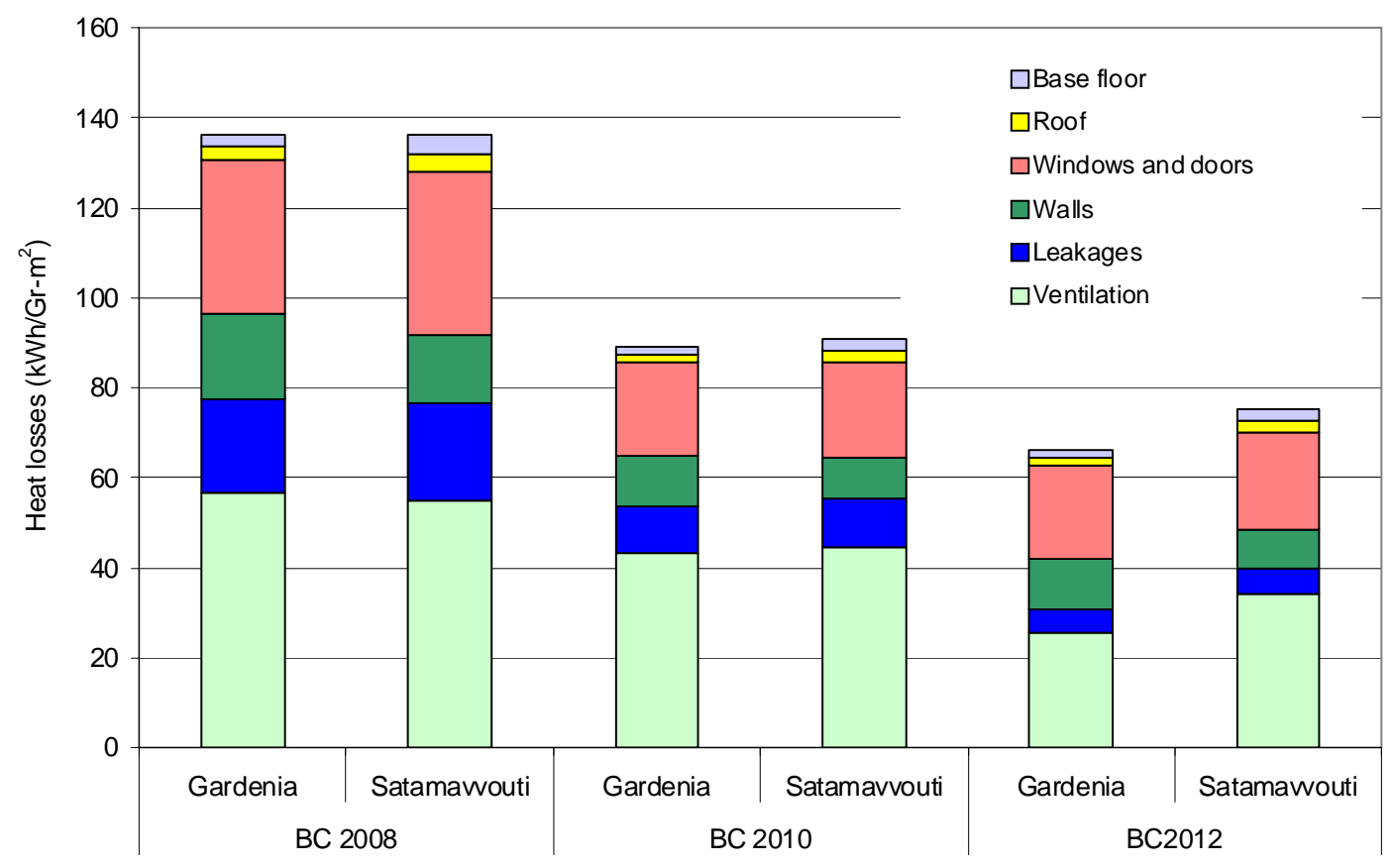

\subsection{Energy Use}

When energy use was considered, it can be clearly seen that heating the space dominated in the buildings constructed according to today's building code (BC 2008), but in the near future domestic hot water is projected to have the major influence, Figure 3. Due to Legionella and other hygienic reasons, the domestic hot water needs to be heated to at least $60{ }^{\circ} \mathrm{C}$. In order to use low temperature heat sources, this brings an extra challenge and might lead to higher costs.

Figure 3. Energy use in the different building cases.

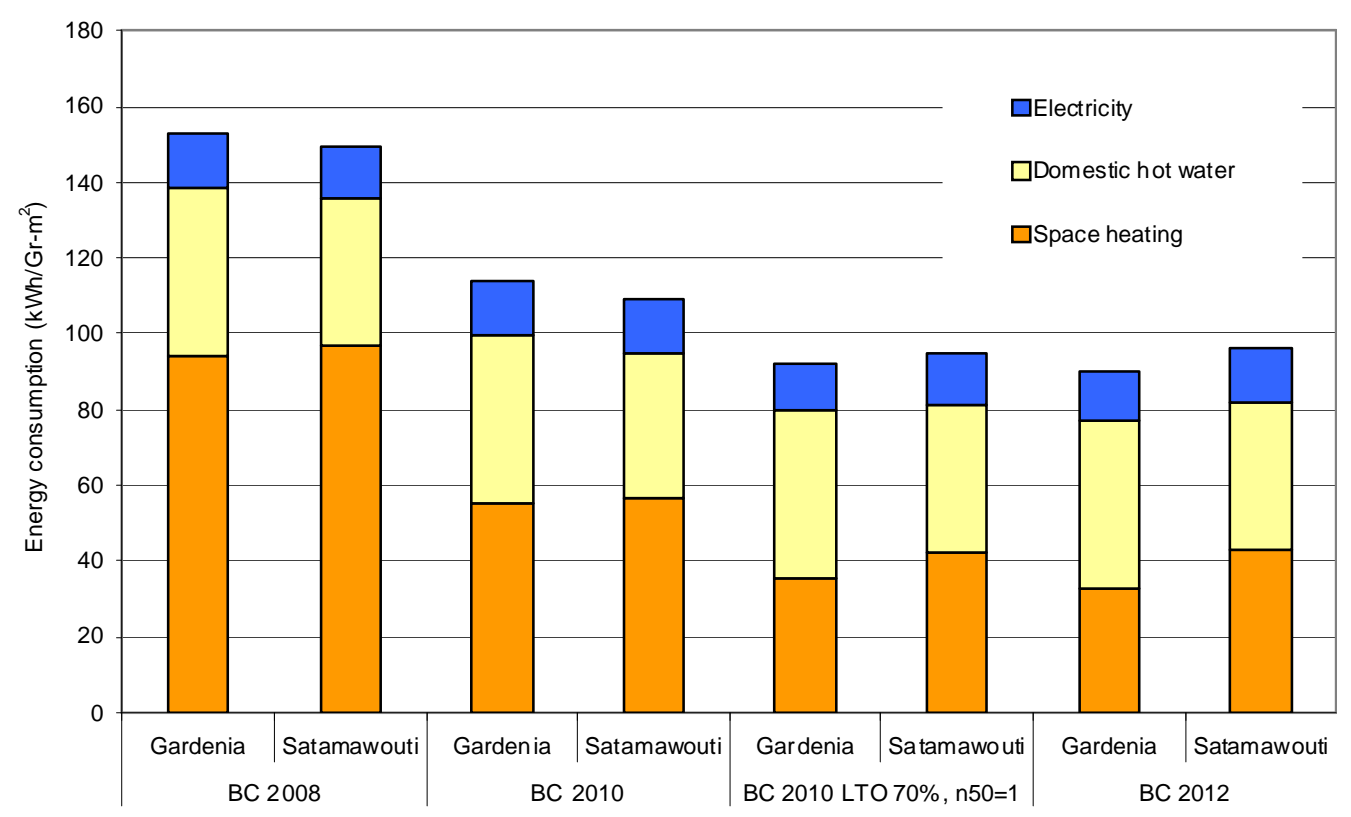


As already mentioned, the share of electricity consumption is only the electricity used for HVAC and corridor lightning. When the user electricity is taken into account the share is much higher. Since the energy consumption levels with the BC 2010 level, but with higher ventilation heat recovery (70\%) and building envelope air tightness, and the BC 2012 level are rather close, in the following calculations only the BC 2012 level is shown.

\subsection{Primary Energy Consumption}

It is well known that district heating is an efficient way to produce electricity and heat. In the calculations, both the average Finnish district heating primary energy factors were used, but also as a case example, the Helsinki power plant's factors were used, in order to see the difference from average. The district heating used from the efficient combined plant (in this example, Helsinki Energy) gave the lowest primary energy consumption, Figure 4. For example if the building envelope U-values and efficient heat recoveries according to BC 2012 are used, but the energy source is ground heat in the district heating area, the primary energy used is $13 \%$ higher compared to the state-of-the-art with district heating. Direct electricity used clearly the most primary energy, but it should be noted that there are also huge differences in electricity between power plants and energy sources. Electricity can be produced from renewable sources as well.

In the area where district heating already exists, ground heat used clearly more primary energy compared to both alternatives in district heating if the same electricity power plant was used. However, ground heat is rather close to average district heating, especially when the energy efficiency of the building is higher (BC 2010 and 2012). Since ground heat needs supporting power in the coldest days, two cases for peak power were calculated: nuclear and coal power plants.

\section{4. $\mathrm{CO}_{2}$ Equivalent Emissions}

Basically, primary energy calculations give us the big picture of $\mathrm{CO}_{2}$ eq emissions. However, the big exception is electricity produced from nuclear power, since that energy source has a high primary energy factor, but nearly no $\mathrm{CO}_{2}$ eq emissions. The emission calculations were interesting, since it shown that efficient district heating as a power source and building with ground heat in addition to nuclear power electricity as a complimentary electricity source performed very close to each other, Figure 5. However, to make the conclusion from these numbers that which of the alternatives we choose has no importance is dangerous. Hypothetically, if the use of district heating would drop dramatically, this would mean that the primary energy factor and $\mathrm{CO}_{2}$ eq emissions from electricity would clearly rise, which would lead to the increase of the ground heat systems emissions.

Again, Figure 5 shows that electricity and domestic hot water use has a high importance in respect to $\mathrm{CO}_{2}$ eq emissions, and the importance increases as the energy efficiency of the building increases. 
Figure 4. Primary energy consumption in different cases.

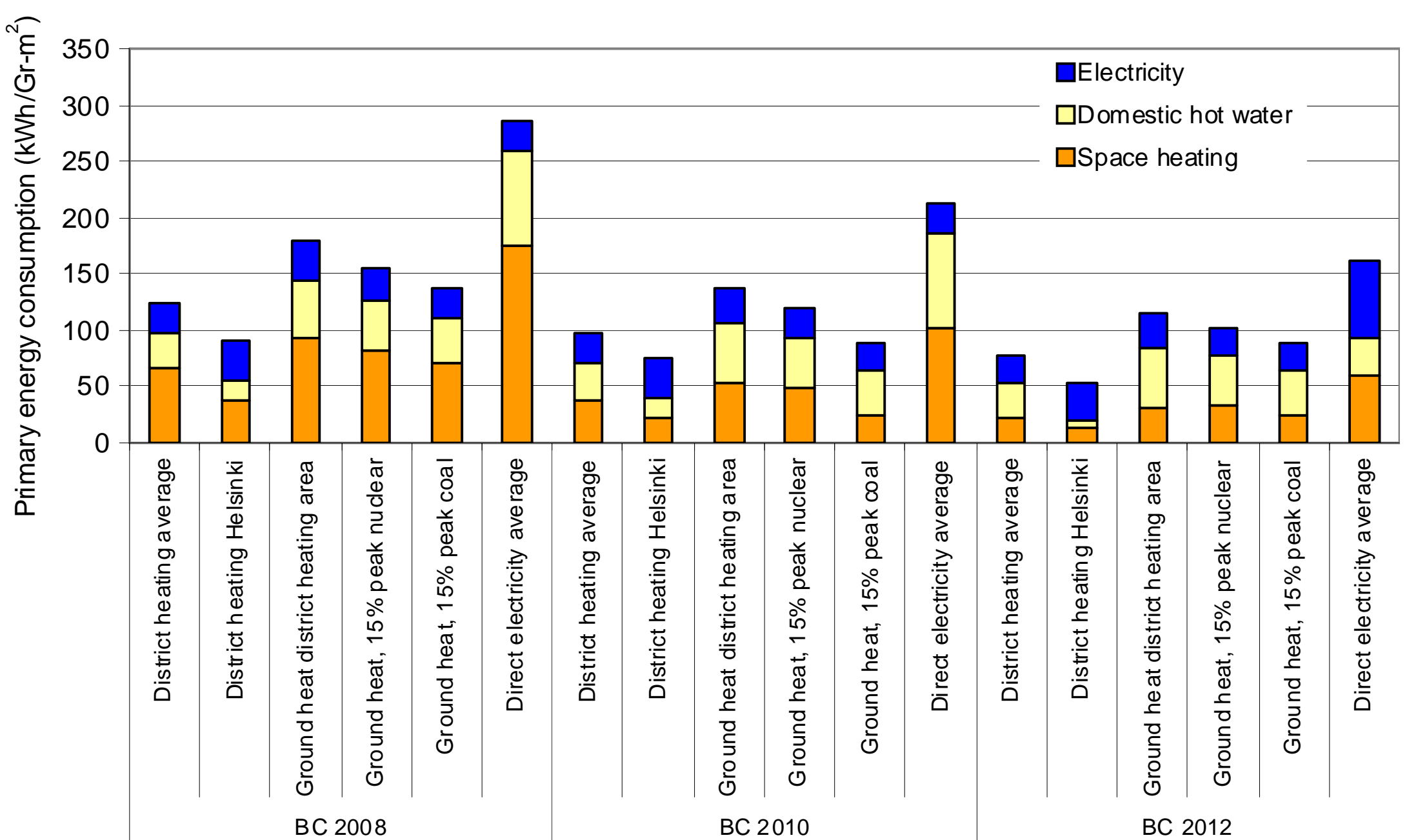


Figure 5. $\mathrm{CO}_{2}$ eq emissions in different cases.

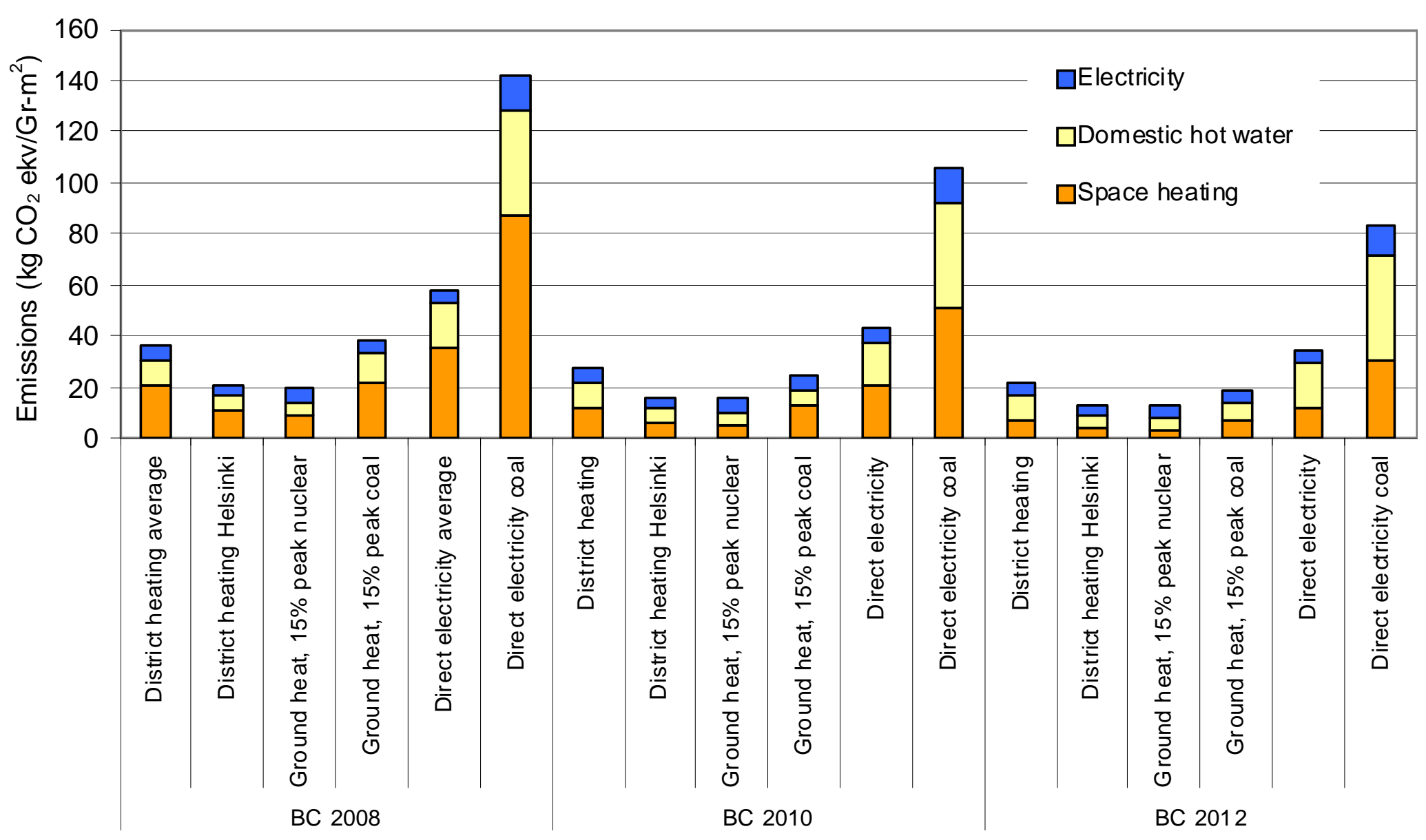




\section{Discussion}

New Finnish national requirements for energy performance (2012 still under development), will lead to approximately a $65 \%$ reduction of the space heating demand in apartment buildings and a $42 \%$ reduction of the total energy demand (including electricity for appliances, but excluding user electricity) in new residential buildings, compared to the demand in buildings built in accordance with the regulations from 2003. Compared to the older building stock, the reductions are clearly larger. A consequence of lower heat demand in new residential buildings, and in other types of buildings as well, is reduced profitability in supplying district heat to newly development areas. Fewer applications for new district heating customers (buildings) may result from the reduced profitability, and electricity-based heating and heating based on fossil fuels may therefore, as a consequence, be chosen as solutions instead. Reduced heat density in new development areas may also lead to reduced profitability in supplying district heat to nearby areas with existing building stock with much higher heat demand. This may be a possible, and highly unintended, development as a result of the new and considerably more stringent requirements for energy performance of new buildings in the building regulations. Hence, lower heat density in new building areas require new focus on the energy supply, with a view to reaching the aims of reducing emissions and electricity use for heating.

Key features of the Finnish energy policy are improved energy efficiency and increased use of renewable energy sources. To obtain the authorities' target regarding a sustainable shift in the energy system, both energy savings and increased use of low polluting energy sources are therefore important priority areas. Constructing low-energy buildings, which in particular are characterized by lower thermal energy demand than in new buildings with the ordinary energy standard, is in accordance with the declared national aim of reducing energy use.

Often energy savings due to energy conservation measures are suspected to be lower in reality than predicted [12-14]. Building characteristics are important in respect to energy use, as determined in many reports. In [15], the influence of building regulations on energy use wasimportant in reducing energy use in new buildings. Similar results were found also in Statistics in Finland and Finnish Ministry of Environment [16]. Thus, energy use associated with building characteristics is decreasing, making the role of the occupant even more important $[13,17,18]$. It had been found $[16,19]$ that energy performance regulations have improved energy conservation. However, the variation in energy use is still large for buildings with the same characteristics. Studies have shown that occupant behavior might play a prominent role in the variation in energy use in different households [6,20,21], but the importance of such influence is still not studied deeply enough. Conversely, the impact of the building's thermal characteristics and behavior on space heating demand has been well studied, quantified and validated from the viewpoint of individual buildings and building simulations, and can now be found in various handbooks, e.g., in [22-26]. On the other hand. only little work has been done on the impact of the thermal characteristics of building stock from a statistical perspective. Furthermore, there is also little work that studies the impact of user/consumer behavior [7,21]. In addition, there is very limited numbers of studies taking into account occupant behavior including building and household characteristics. 


\subsection{Renewable Energy Sources}

Presently, the share of renewable energies in the built environment is very modest, and aims at covering only the base load. Both at national and international level, the targets for energy efficiency and share of renewable production imply a steep increase of intermittent renewable energy. For the built environment, it is envisaged that the total yearly energy demand could be covered by thermal and electrical energy produced from renewable sources, generated within the built environment. To fulfill this ambition, almost $20 \%$ of the total current energy demand should be produced at district level, apart from the contribution at building level.

The ambition in sustainable development in the built environment is to enable the utilization of the full potential of renewable energy (up to $100 \%$ of the energy demand on the district level). Implementing such a large share of renewable energies with present day technology faces a number of challenges. The renewable energy supply such as solar or wind energy has a fluctuating character, which is obviously problematic to demand where the need is usually rather constant or not at the same cycle as the supply. In addition, the peak supply from renewable energies can be much higher that demand and the excess energy cannot be harvested. Especially in northern climates, the space needed for local renewable production might become disproportionally large (area of collectors, etc.). In addition, the location of the building/district is not always suitable to some renewable sources.

The wide spread of renewable energy technologies (e.g., solar, wind, biogas, etc.) and the implementation of energy-saving methods could save up to 12\% [27] of energy for EU countries by 2016 [28]. In addition, funding can help for isolated cases of these technologies; a good example is the solar by-law in Spain, which allows tax rebate for building, installations and works equipped with solar systems for self-consumption. Another example is funding of energy-efficient houses in Germany, where the direct funding (for "KfW-Effizienzhaus 100” introduced from October 2009) is $17.5 \%$ [29].

In a district, the investment can be shared by the buildings within the district. District level consideration reduces carrying costs and increases the value of new buildings as early as in the planning phase. The introduction of branding for new construction as well as retrofit projects aims to preserve and even increase the value of construction objects by $5-30 \%$ throughout their lifetime. The same consideration and application of management system and business models makes retrofit decisions easier for the owners, thus increasing the building value for both users (due to decreased energy costs) and owners (due to shorter return on the investment period) [30].

In residential buildings, the integrated design of a building, taking into account the complete life-cycle analysis (considering the embodied energy of the building materials, reducing the demand through a cyclic process of design and energy simulation, implementing a highly efficient building component and systems and using building automation for the control and metering), can reduce the energy consumption of the building by $40 \%$ throughout its complete life cycle, and by $75 \%$ during its operation. In a 60 unit apartment building (4,150 $\mathrm{sm}^{2}$ net area), this leads to a reduction of approximately $350 \mathrm{MWh} /$ year and $90 \mathrm{tnCO}_{2} /$ year.

If these energy efficient buildings are in addition integrated to local energy networks, enabling the use of local renewable energies adds additional savings: reduced energy transfer losses are 
around $10 \%$, but more importantly, the $\mathrm{CO}_{2}$ emission is reduced dramatically by up to $70 \%$ when renewable energies and local waste energies are used.

The building integration to local networks has a huge impact on existing district and buildings, since even without massive retrofitting, the $\mathrm{CO}_{2}$ emissions can be cut down to 40-60\%. (Comparison between coal and ground heat as energy sources).

$\mathrm{CO}_{2}$ emissions can be reduced by $20 \%$ or more only through a change in user behavior within buildings.. The same can be stated for energy use within buildings in general. Therefore, user behavior is a powerful lever to be considered both in the context of the building and district level. The approach of going beyond technical solutions for energy efficiency, but to combine them with specific and user friendly interfaces, leads to a substantial increase of the efficiency of the applied technologies.

\section{Conclusions}

In the future, electricity and domestic hot water use will be of high importance in respect to energy consumption, and therefore also $\mathrm{CO}_{2}$ eq emissions. The importance increases as the energy efficiency of the building increases. When renewable energy sources are used, they typically have lower temperature levels. That is very complicated in respect to domestic hot water heating, since it needs to be heated up to $60^{\circ} \mathrm{C}$ due to Legionella and other hygienic reasons.

There are big differences between average Finnish energy production and single power plants, e.g., the $\mathrm{CO}_{2}$ eq emissions might nearly double depending of the energy source and power plant type.

Both a building with an efficient district heating as a power source, and building with ground heat in addition to nuclear power electricity as a complimentary electricity source performed very similarly to each other in respect to $\mathrm{CO}_{2}$ eq emissions. However, to make from this the conclusion that it is not important which alternative we choose is dangerous. Hypothetically, if the use of district heating would drop dramatically, the primary energy factor and $\mathrm{CO}_{2}$ eq emissions from electricity would rise, the leading to the increase of the ground heat systems emissions.

The results can be also applied to retrofitting cases; it clearly indicates that in areas with co-generation district heating, massive renovation actions to improve the thermal properties of the exterior envelope do not have a high importance, since the $\mathrm{CO}_{2}$ emissions are already low. However, if an old building is close to district heating area (co-generation), it is more efficient to change the old electricity heating system to district heating rather than to start renovating the envelope, if the envelope does not need the renovation for structural purposes. Obviously, if renovation is needed then of course it is beneficial to insulate the envelope as well.

Problems in the yearly calculations arise due to the fact that we always exclude that it is also very important, sometimes even crucial, to consider when energy is needed. An example of that might be ground heat solutions used in buildings, which cannot serve in very cold days but need typically supportive power in those days. In respect to emissions, this can be problematic if the extra power supplied to markets is produced with a polluting energy source. On the other hand, in the buildings where cooling is needed, ground heat has the advantage that it can be used during cooling periods as well.

The building integration to local networks supplying renewable energy has a huge impact on existing district and buildings, since even without massive retrofitting, the $\mathrm{CO}_{2}$ emissions can be cut 
down to $40-60 \%$. Thus, for future, it is not only the energy saving, but even more, the source of the energy and maximum use of local renewable energies.

\section{Acknowledgements}

This study was done as a part of Skanska M\&E Finland energy efficient building development. The Skanska is greatly acknowledged for giving this opportunity to deeper analyze the energy efficiency and current building concepts.

\section{References and Notes}

1. EU Energy and Transport in Figures, Statistical Pocket Book 2007/2008; European Communities: Brussels, Belgium, 2008.

2. Summary of the Impact Assessment; Communication Staff Working Document, Accompanying Document to the Proposal for a Recast of the Energy Performance of Buildings Directive (2002/91/EC); COM (2008) 755/SEC(2008) 2821; Commission of the European Communities: Brussels, Belgium, 2008.

3. A European Strategic Energy Technology Plan (SET-PLAN); COM (2007) 723 Final; Commission of the European Communities: Brussels, Belgium, 2007; Available online: http://eur-lex.europa.eu/LexUriServ/LexUriServ.do?uri=COM:2007:0723:FIN:EN:PDF (accessed on 22 November 2007).

4. Itard, L.; Meijer, F. Towards a Sustainable Northern European Housing Stock: Figures, Facts and Future; IOS Press: Amsterdam, The Netherlands, 2009.

5. Towards Energy Efficient Buildings in Europe; Final Report; EuroACE: London, UK, 2004; Available online: http://www.euroace.org/EuroACE\%20documents/050731\%20Towards\%20 Energy\%20Efficient\%20Buildings\%20in\%20Europe\%20(Jul\%2005\%20update).pdf (accessed on 31 January 2010)

6. Citherlet, S.; Clarke, J.A.; Hand, J. Integration in building physics simulation. Energ. Bldg. 2001, 33, 451-461.

7. Jonsson, A. Tools and methods for environmental assessment of building products -methodological analysis of six selected approaches. Bldg. Environ. 2000, 35, 223-238.

8. IDA Simulation Environment; Available online: www.equa.se (accessed on 31 January 2010)

9. Sahlin, P. Modelling and Simulation Methods for Modular Continuous Systems in Buildings; Ph.D. Thesis; Royal Institute of Technology: Stockholm, Sweden, 1996.

10. Sahlin, P.; Sowell, E.F. The Neutral Model Format for Building Simulation; Swedish Institute of Applied Maths, Chalmers Teknikpark: Gothenburg, Sweden, 1996.

11. Sahlin P.; Bring A. IDA SOLVER—a tool for building and energy systems simulation. In Proceedings of the BEPAC Conference “BEP'91”, Nice, France, 14-19 August 1991; pp. 576-582.

12. Branco, G.; Lachal, B.; Gallinelli, P.; Weber, W. Predicted versus observed heat consumption of a low energy multifamily complex in Switzerland based on long-term experimental data. Energ. Bldg. 2004, 36, 543-555. 
13. Haas, R.; Auer, H.; Biermayr, P. The impact of consumer behavior on residential energy demand for space heating. Energ. Bldg. 1998, 27, 195-205.

14. Hirst, E.; Goeltz, R. Comparison of actual energy saving with audit predictions for homes in the North Central Region of the USA. Bldg. Environ. 1985, 20, 1-6.

15. Leth-Petersen, S.; Togeby, M. Demand for space heating in apartment blocks: measuring effect of policy measures aiming at reducing energy consumption. Energ. Econ. 2001, 23, 387-403.

16. Statistics Finland Homepage; Available online: http://www.stat.fi/index_en.html (accessed on 31 January 2010).

17. De Groot, E.; Spiekman, M.; Opstelten, I. Dutch research into user behavior in relation to energy use of residences. In Proceedings of 25th International PLEA Conference on Passive and Low Energy Architecture, Dublin, Ireland, 22-24 October 2008; Available online: http://architecture.ucd.ie/Paul/PLEA2008 (accessed on 31 January 2010)

18. Papakostas, K.T.; Sotiropoulos, B.A. Occupational and energy behavior patterns in Greek residences. Energ. Bldg. 1997, 26, 207-213.

19. Beerepoot, M.; Beerepoot, N. Government regulations as an impetus for innovations. Evidence for energy performance regulation in the Dutch residential building sector. Energ. Policy 2007, 35, 4812-4825.

20. Jeeninga, H.; Uyterlimde, M.; Uitzinger, J. Energy Use of Energy Efficient Residences; Report ECN-C-01-072; Energy Research Centre of The Netherlands (ECN): Petten, The Netherlands, 2001.

21. Karjalainen, S. The Characteristics of Usable Room Temperature Control; Ph.D. Thesis; Helsinki University of Technology: Espoo, Finland, 2008.

22. Kalema, T.; Pylsy, P.; Hagengran, P.; Johannesson, G.; Airaksinen, M.; Dokka, T. H.; Öberg, M.; Pöysti, M.; Rapp, K.; Keski-Opas, J. Nordic Thermal Mass-Effect on Energy and Indoor Climate; Report 184; Institute of Energy and Process Engineering, Tampere University of Technology: Tampere, Finland, 2006.

23. Clarke, J.A.; Clarke, J. Energy Simulation in Building Design; Butterworth-Heinemann: Woburn, MA, USA, 2001.

24. ASHRAE Handbook-Fundamentals, 2005; Available online: www.ashrae.org (accessed on 31 January 2010).

25. Thermal Performance of Buildings_Calculation of Energy Use for Space Heating; ISO 13790; 2004; Available online: www.iso.org (accessed on 31 January 2010).

26. Energy Performance of Buildings_Calculation of Energy Use for Space Heating and Cooling; ISO 13790; 2008; Available online: www.iso.org (accessed on 31 January 2010).

27. Directive 2006/32/EC of the European Parliament and of the Council of 5 April 2006 on Energy End-Use Efficiency and Energy Services and Repealing Council Directive 93/76/EEC; The Council of the European Communities: Brussels, Belgium, 2006.

28. COUNCIL DIRECTIVE 93/76/EEC of 13 September 1993 to Limit Carbon Dioxide Emissions by Improving Energy Efficiency (SAVE); The Council of the European Communities: Brussels, Belgium, 1993.

29. Energiefoerdderung Info Homepage; Available online: http://www.energiefoerderung.info/ (accessed on 31 January 2010). 
30. The Return on Investment for Solar Photovoltaics, Residential Applications; Available online: http://www.sustainableenergygroup. com/SolarROI.html (accessed on 31 January 2010).

(C) 2010 by the authors; licensee Molecular Diversity Preservation International, Basel, Switzerland. This article is an open-access article distributed under the terms and conditions of the Creative Commons Attribution license (http://creativecommons.org/licenses/by/3.0/). 